\title{
GCU
}

Glasgow Caledonian

University

University for the Common Good

\section{Plagiarism governance in nurse education: dispositions, dimensions and tensions} Welsh, Marion

Published in:

Nurse Education in Practice

DOI:

10.1016/j.nepr.2017.08.011

Publication date:

2017

Document Version

Author accepted manuscript

Link to publication in ResearchOnline

Citation for published version (Harvard):

Welsh, M 2017, 'Plagiarism governance in nurse education: dispositions, dimensions and tensions', Nurse Education in Practice, vol. 27, pp. 22-28. https://doi.org/10.1016/j.nepr.2017.08.011

\section{General rights}

Copyright and moral rights for the publications made accessible in the public portal are retained by the authors and/or other copyright owners and it is a condition of accessing publications that users recognise and abide by the legal requirements associated with these rights.

Take down policy

If you believe that this document breaches copyright please view our takedown policy at https://edshare.gcu.ac.uk/id/eprint/5179 for details of how to contact us. 


\title{
PLAGIARISM GOVERNANCE IN NURSE EDUCATION: DISPOSITIONS, DIMENSIONS
} AND TENSIONS

\begin{abstract}
The reality of managing plagiarism in nurse education is indicative of multilayered and cumulative governance processes, which exist to fit with the needs of both the higher education institution and that of the Professional Statutory and Regulatory Body. However, the relationship between these entities is diffuse, particularly when this involves major plagiarism by post-qualified learners. This study sought to explore the strategic governance of plagiarism in Scottish higher education institutions offering nurse education and its articulation with the professional requirements of nurse education. The design involved a retrospective quantitative documentary analysis of plagiarism policies within 11 Scottish higher education institutions and a national on-line survey involving nurse educators with an active teaching role $(n=187)$. The documentary analysis demonstrated deficits and variations in how Scottish higher education institutions communicated the dimensions of plagiarism, and its subsequent management. Statistically significant findings from the on-line survey provided a clear mandate for educational providers to make visible the connectivity between organisational and professional governance processes to support responsive and proportional approaches to managing plagiarism by nurse learners. Significant findings also confirmed role implications and responsibilities, which nurse educators in this study, viewed as primarily pedagogical but crucially remain professionally centric.
\end{abstract}

\section{Key words}

Plagiarism

Plagiarism governance, policy and practice

Professional education and nurse learners

Nurse educators

Fitness to Practise

Quantitative

Cross-sectional

\section{Highlights}

- The relationship between higher education institutions' plagiarism policy and professional body governance lacks clarity

- Managing plagiarism has wide ranging implications for nurse educators 
- Plagiarism is primarily a pedagogical issue

- Fitness to Practice processes provide the forum to manage major plagiarism, irrespective of the nurse learner's pre or post registration status

\section{INTRODUCTION}

Across the international higher education arena, the occurrence of student plagiarism has come to symbolise a complex and emotive issue, which presents educators with omnipresent challenges (Baird and Dooey, 2014; Walker and White, 2014). Consequently, higher education institutions across the globe have striven to foster a culture of plagiarism avoidance using a variety of systems and innovations. Whilst this has culminated in the realisation that its prevention and management requires being pedagogically orientated, this needs to operate in tandem with effective institutional governance (Sutherland-Smith, 2014).

Although higher education institutions have responded proactively in articulating policies, which convey anti-plagiarism governance (Smedley et al, 2015) this landscape becomes nuanced and cumulative when the foreground is professional learning, with its inherent expectations regarding professionalism and competence. Within the UK, the Nursing and Midwifery Council, as the Professional Statutory and Regulatory Body, dictate these requirements across the broad arena of nurse education (Nursing and Midwifery Council 2001, 2004, 2006, 2008, 2010, 2015b). Consequently, for nurse educators, managing plagiarism becomes intensified when driven by the duality of governance, that is, that prescribed by the higher education institution and that by the Professional Statutory and Regulatory Body. However, in the UK setting, the relationship between educational providers and the Nursing and Midwifery Council at a policy level appears obtuse, particularly when this accords with major plagiarism and involves post-qualified nurse learners. Whilst plagiarism irrefutably challenges the principles of academic integrity, in nurse education it also appears to test expectations of professionalism in learning as well as the role and responsibilities of nurse educators. 


\section{BACKGROUND}

Within the global context of nurse education, the coalescing of knowledge and skills acquisition, with unimpeachable ethical behaviour, are mandatory professional requirements for professional learners (Akhatar-Danesh et al, 2011). From a UK perspective, any infringement concerning a professional learners' conduct, behaviour or attitude may cast doubt over entry to, or continuance on, the professional register (Nursing and Midwifery Council, 2015a, 2015b). In this context, instances of plagiarism have drawn specific comment by the Nursing and Midwifery Council, equating this with dishonesty that falls below professional expectations. The seriousness with which the Nursing and Midwifery Council views major plagiarism is tangible and has received the full weight of professional governance and sanction. In the past decade, higher education institutions have referred several cases of major plagiarism by post-qualified learners to the Nursing and Midwifery Council's Conduct and Competence Panel, which have thereafter been judged on the basis of 'literary theft'. As a result, registrants have been cautioned and or suspended from the professional register by demonstrating serious misjudgement and, consequently, impairing their Fitness to Practise (Nursing and Midwifery Council, 2016).

As an antecedent of professional governance, the Nursing and Midwifery Council required higher education institutions to have in place robust 'Fitness to Practise' processes to oversee and adjudicate in situations where learners, in the context of academic study, demonstrate non-compliance with their code of conduct (Nursing and Midwifery Council, 2015b). However, a Fitness to Practise panel's remit and powers are wholly dependent on the registration status of the learner. For example, within pre-registration nurse education, cases of major plagiarism can be arbitrated and penalties conferred including dismissal from the programme, thereby acting as professional gatekeeper. However, in the post-qualified context whilst the same panel has similar powers to administer academic sanctions, it has no jurisdiction in assessing a registrant's Fitness to Practise. It does however have discretion to refer, or not, a registrant to the Nursing and Midwifery Council's Conduct and Competence Panel should they consider their behaviour raises concerns about a registrant's Fitness to Practise. The premise being that within the higher education institution, nurse learners are subject to additional professional standards and processes. 
The reverberations of how plagiarism is governed and managed in nurse education have gathered pace over the past decade, yet much of this work is opinionated rather than empirical. Nonetheless, nurse educators have adopted staunch perspectives on plagiarism that ensures that a triad of interwoven debate points exist, centring on behavioural ethics, suboptimal learning and a precursor for professional misconduct (Kenny, 2007; Brown et al., 2008; McCrink, 2010). Whilst ethical concerns hinge on the deceptiveness of nurse learners to gain an unfair advantage (Park et al., 2013), the pedagogical outcomes align with deficits in the learner's theoretical knowledge base, resulting in impeded critical thinking skills culminating in the potential to impair professional practice (Bavier, 2009; Kennedy, 2011). These arguments occur in parallel with plagiarism being argued as a precursor for future unprofessional practice, based on this type of academic misconduct constituting a transferable learned behaviour (Fontana, 2009; Langone, 2007; Pence, 2012). In this context, Hilbert's $(1985,1987)$ studies are frequently cited as providing proof this positive correlation between plagiarism and future malpractice. However, these small USA based surveys used an 11-item questionnaire to explore a range of fraudulent-type behaviours with 3 questions related to plagiarism and these resulting in negligible findings. Overall, cumulative calculations for all types of dishonest behaviours, in both Hilbert's $(1985,1987)$ studies demonstrated a significant correlation between academic fraud and clinical misconduct. Hilbert (1987) concluded that if nurse learners cheat in the classroom setting then their clinical practice should also come under scrutiny. Nevertheless, Hilbert (1987) hypothesised that this type of aberrant behaviour might be due to inherent personality traits as opposed to the situation variable of the academic setting.

The impact of plagiarism within nurse education has gone largely unexplored, with only Paterson et al.'s (2003) Canadian study evidencing that nurse educators' construction of plagiarism was influenced by their professional values and negative prior experiences of dealing with it. These findings illuminated discomfort in occupying the dual role of teacher and plagiarism detective, which subsequently affected how they implemented governance. Whilst the challenges of plagiarism have been ubiquitously conveyed within mainstream educational literature, within nurse education these remain underrepresented. This study was conducted to explore nurse educators' opinions of the strategic governance of plagiarism in Scottish 
higher education and how this should align with the Nursing and Midwifery Council's requirements for nurse education.

\section{METHODS}

Undertaken as a national cross-sectional study, in two sequential phases, this study's mainly quantitative design entailed a retrospective documentary analysis of plagiarism policies across the 11 Scottish higher education institutions that offer nurse education and an on-line survey of nurse educators' opinions on plagiarism governance.

As a forerunner to developing the on-line survey, a retrospective documentary analysis was undertaken to explore the extent to which plagiarism was defined, contextualised and provided bespoke direction for professional educators. Notable outcomes at this juncture were the deficits and variations in how Scottish higher education institutions communicated the dimensions of plagiarism, and its subsequent management. A detailed search had revealed no pre-existing questionnaire to inform the on-line survey therefore a bespoke tool was developed to explore 3 inter-related constructs: communicating the concept of plagiarism in higher education policy; engaging with the duality of plagiarism governance in higher education; and role implications and dimensions.

Ethical approval was secured and gatekeeper permission to approach nurse educators was provided by 10 of the 11 Scottish higher education institutions. This resulted in a relatively small target population of nurse educators with an active teaching role $(n=431)$. Consequently, recruitment adopted a census approach, which ensured that the entire target population had an equal opportunity to participate, thus offsetting potential issues of sampling bias or error (Robson, 2011). The survey questionnaire consisted of a 6-point Likert scale to explore a range of statements reflecting the aforementioned constructs. The tool's construction avoided coercing participants into making a forced choice response; consequently, a neutral midpoint of 'Neither/Nor' was included, despite the potential for this to result in central tendency bias (Cohen et al., 2011). In acknowledging the complexities of plagiarism, it was also important to consider that some participants may exhibit uncertainty as opposed to having a definitive opinion or being impartial. Consequently, the tool's rating scale reflected 'Strongly Disagree; Disagree; Neither/Nor; Agree; Strongly Agree; Unsure'. 
The survey tool also included the opportunity for participants to simultaneously offer, should they so desire, additional free-text 'open-ended' commentary for any of the statements within the tool. In this context, this study utilised mixed data sources to contribute to the findings. The questionnaire's validity was established by senior academics with extensive experience in the strategic and operational governance of plagiarism across a range of professional disciplines (nursing, engineering and occupational therapy). The questionnaire was then pilot-tested with 8 healthcare educators from podiatry, occupational therapy, physiotherapy, radiography and social work. These educators were specifically targeted as they have similar professional governance requirements to nursing, that is, a mandate for learners to demonstrate exemplary behaviours located within Fitness to Practise. Furthermore, as census sampling was being utilised, this approach avoided contamination. Following minor modifications to the questionnaire, pre-test reliability was assessed using Cronbach's Alpha, which resulted in coefficient score of .788 , regarded as good for social science research (George and Mallery, 2003).

Potential participants were contacted via email and provided with study information and an electronic link to the SurveyMonkey@ questionnaire. Confidentiality and anonymity were assured using a web-based tool, which avoided the requirement to provide identifiable biographical information about the respondent or their institution, nor did it permit identification of IP addresses. The response rate was $44 \%(n=187)$, which despite discarding 14 incomplete questionnaires still exceeded expectations for a web-based educational survey, which in prior studies range from $21 \%$ to $36.3 \%$ (de Jager \& Brown, 2010; Sax, et al, 2003). A lower Cronbach's Alpha post-test score of .643 was obtained, however Tavakol and Dennick (2011) advises cautious interpretation as a score may be affected by the number of participants and/or the construction of the questionnaire, in terms of the number of items and constructs used therein. 


\section{RESULTS}

Of 173 participants who fully completed the survey, the most prevalent academic group were lecturers $(78 \% n=135)$ followed by senior lecturers $(18.5 \% n=32)$ and Head of Department/Dean/Professor $(3.5 \% n=6)$. The opinions of nurse educators were analysed using Chi-squared analysis $\left(\chi^{2}\right)$. As no previous quantitative work appeared to have been undertaken specific to plagiarism governance, the level of significance was set as $a=0.05$. The 681 individual 'free-text' comments received were analysed using Braun and Clarke's (2006) thematic analysis framework, a process that resulted in the emergence of key themes.

\section{Communicating the concept of plagiarism in higher education policy}

In exploring the distinctions and dimensions of plagiarism governance, nurse educators responded to 7 statements (Table 1). These statements sought to explore findings from the documentary analysis, which confirmed variations and deficits in how plagiarism was defined, managed and sanctioned within and across Scottish higher education institutions' policies. Nurse educators' responses demonstrated statistical significance for all 7 statements, which in practical terms calls for consistency, explicitness and support for standardised application across all subject areas.

\begin{tabular}{|c|c|c|c|c|c|c|}
\hline \multirow{2}{*}{$\begin{array}{l}\text { Table } 1 \\
\text { Statement }\end{array}$} & \multirow[b]{2}{*}{ Total } & \multicolumn{2}{|c|}{ Reject } & \multicolumn{2}{|c|}{ Endorse } & \multirow[b]{2}{*}{$x^{2}$} \\
\hline & & $f$ & $\%$ & $f$ & $\%$ & \\
\hline $\begin{array}{l}\text { 1. Plagiarism is 'passing off someone else's work as } \\
\text { your own' conveys a contemporary understanding }\end{array}$ & 160 & 31 & 19.4 & 129 & 80.6 & $60.2^{*}$ \\
\hline $\begin{array}{l}\text { 2. A Higher Education Institution's definition of } \\
\text { plagiarism should include the phrase 'whether } \\
\text { intentionally or unintentionally' }\end{array}$ & 162 & 15 & 9.3 & 147 & 90.7 & $107.56^{*}$ \\
\hline $\begin{array}{l}\text { 3. A Higher Education Institution's definition should } \\
\text { provide examples such as direct copying, close } \\
\text { paraphrasing collusion self-plagiarism etc. }\end{array}$ & 170 & 4 & 2.4 & 166 & 97.6 & $154.37^{*}$ \\
\hline $\begin{array}{l}\text { 4. Higher Education Institutions should adopt a } \\
\text { standard definition of plagiarism and this should be } \\
\text { universally applied within all academic disciplines }\end{array}$ & 157 & 12 & 7.6 & 145 & 92.4 & $112.66^{*}$ \\
\hline $\begin{array}{l}\text { 5. Poor academic practice e.g. non-attribution to } \\
\text { source, poor paraphrasing should not be defined as } \\
\text { plagiarism }\end{array}$ & 143 & 56 & 39.2 & 87 & 60.8 & $6.72^{*}$ \\
\hline $\begin{array}{l}\text { 6. A Higher Education Institution's definition should } \\
\text { state that learning may be compromised as a result } \\
\text { of plagiarising the work of others, either intentionally } \\
\text { or unintentionally }\end{array}$ & 146 & 18 & 12.3 & 128 & 87.7 & $82.87^{*}$ \\
\hline $\begin{array}{l}\text { 7. A Higher Education Institution's definition of } \\
\text { plagiarism should not be open to individual } \\
\text { interpretation based on an educator's prior } \\
\text { conceptions }\end{array}$ & 162 & 15 & 9.3 & 147 & 90.7 & $107.55^{*}$ \\
\hline
\end{tabular}


Notes: $f=$ frequency; $\%=$ percentage of total responses; ${ }^{*} p<.05$

In the higher education setting plagiarism denotes an all-encompassing term, which captures the act of academic wrongdoing, which thereafter higher education institutions require to manage in accordance with their code of conduct. However, the act of plagiarism is subsequently deconstructed and reduced to classify a specific type of deviant behaviour. Nurse educators' opinions on how plagiarism should be behaviourally categorised are evidenced in Table 2. All 3 statements demonstrated endorsement, with two reaching statistical significance $(\# 8,9)$ indicating although plagiarism may be the nomenclature, its delineation needs to capture non-intent to cheat and moreover should be exempt from being considered an amoral infringement. However, should intent be proven, then the use of terms such as 'cheating', 'rule breaking', 'theft' (literary, non-legal context) and 'fraud' were acceptable.

\begin{tabular}{|c|c|c|c|c|c|c|}
\hline \multirow{2}{*}{$\begin{array}{l}\text { Table } 2 \\
\text { Statement }\end{array}$} & \multirow[b]{2}{*}{ Total } & \multicolumn{2}{|c|}{ Reject } & \multicolumn{2}{|c|}{ Endorse } & \multirow[b]{2}{*}{$x^{2}$} \\
\hline & & $F$ & $\%$ & $f$ & $\%$ & \\
\hline $\begin{array}{l}\text { 8. Whilst defining plagiarism may include reference } \\
\text { to an intentional or unintentional act, not all } \\
\text { instances of plagiarism should be regarded as } \\
\text { cheating }\end{array}$ & 162 & 21 & 13.0 & 141 & 87.0 & $88.88^{*}$ \\
\hline $\begin{array}{l}\text { 9. Higher Education Institutions should use terms } \\
\text { such as theft, fraud, cheating and rule breaking, } \\
\text { within their plagiarism policies to categorise this type } \\
\text { of intentional academic misconduct }\end{array}$ & 134 & 37 & 27.6 & 97 & 72.4 & $26.86^{*}$ \\
\hline $\begin{array}{l}\text { 10. Higher Education Institutions should avoid } \\
\text { moralising commentary such as 'dishonesty', } \\
\text { 'deception' and 'misappropriation' within their } \\
\text { plagiarism policies }\end{array}$ & 138 & 65 & 47.1 & 73 & 52.9 & .46 \\
\hline
\end{tabular}

Despite the consensus, within the supplementary qualitative commentaries, representing the theme of contextual communication, some nurse educators demonstrated tension and discomfort regarding the behavioural labelling of nurse learners:

'There should be real plagiarism [intentional] and poor scholarship [unintentional] these are the real distinctions to be made. All this is made more difficult with the blithe use of Turnitin and the like and cut off \% levels of plagiarism or poor scholarship leading to letters going out from committees with offensive labels such as 'cheating, plagiarism and poor scholarship'. Once these letters are out the damage is done whatever the outcome'

'The word 'cheating' may be useful, but the other words 'theft' and 'fraud' have such negative connotations that are not useful'

"These are derogatory words, which will make people evaluate themselves negatively, when they may have unintentionally carried out an act. I think we should 
show students more respect than this. It's all about discerning the context and student intention'.

'These words to me convey bullying, harassment and disrespect'

\section{Engaging with the duality of plagiarism governance in higher education}

The justification for the alignment between educational and professional governance processes being transparent arguably hinges on the role the former has as provider of nurse education within which lie key responsibilities to ensure students are fit to practise based on the contact they have with patients and service users. Whether this occurs in a quasiprofessional context, such as pre-registration education, or as post-qualified registrant, for example, study to become a non-medical prescriber, the level of accountability which exists for higher education institutions transcends simply certifying academic achievement. Consequently, pragmatic plagiarism governance might suggest that in managing with major plagiarism, normally accepted as clear intent to deceive, repeated infringements and occurring at progressed level of academic study (Wagner 2014), higher education institutions would cross-refer to relevant Nursing and Midwifery Council governance processes when this involves a professional learner.

In this study, the documentary analysis demonstrated only 2 out 11 Scottish higher education institutions' strategic policies on plagiarism cross-referred the reader to professional learning requirements and processes, vis-à-vis Fitness to Practise. Advancing this line of inquiry with nurse educators (Table 3 ) resulted in statistically significant outcomes (\#11), which support the connectivity between institutional and professional governance policy processes.

\begin{tabular}{|c|c|c|c|c|c|c|}
\hline \multirow{2}{*}{$\begin{array}{l}\text { Table 3 } \\
\text { Statement }\end{array}$} & \multirow[b]{2}{*}{ Total } & \multicolumn{2}{|c|}{ Reject } & \multicolumn{2}{|c|}{ Endorse } & \multirow[b]{2}{*}{$x^{2}$} \\
\hline & & $f$ & $\%$ & $f$ & $\%$ & \\
\hline $\begin{array}{l}\text { 11. Higher Education Institutions should not need to cross- } \\
\text { refer their strategic policies on plagiarism, such as } \\
\text { assessment regulations, code of conduct, with } \\
\text { professional governance requirements, i.e. Fitness to } \\
\text { Practise processes }\end{array}$ & 148 & 99 & 66.9 & 49 & 33.1 & $16.89^{*}$ \\
\hline $\begin{array}{l}\text { 12. Whether occurring in the pre or post-registration } \\
\text { context, minor breaches of plagiarism should be formally, } \\
\text { as opposed to informally, managed at a departmental level }\end{array}$ & 163 & 22 & 13.5 & 141 & 86.5 & $86.87^{*}$ \\
\hline $\begin{array}{l}\text { 13. In upholding cases of major plagiarism by post- } \\
\text { registration students, an Higher Education Institution's } \\
\text { Fitness to Practise Panel should always refer these cases } \\
\text { to the Nursing and Midwifery Council }\end{array}$ & 129 & 62 & 48.1 & 67 & 51.9 & 0.19 \\
\hline
\end{tabular}


14. Informal plagiarism management, i.e. that which avoids

invoking departmental or Fitness to Practise processes,

limits approaches to maintaining academic and

professional integrity

Focused on major plagiarism by post-qualified learners, a flurry of additional comments were triggered by statement 13 , "In upholding cases of major plagiarism by postregistration students, an Higher Education Institution's Fitness to Practise Panel should always refer these cases to the Nursing and Midwifery Council", demonstrating divergent opinions, which affiliated with the theme of governing and managing fairly:

'How can it be any other way?'

'The responsibility should lie with the Higher Education Intuition's Fitness to Practise committee'

However, opinions also stressed the need for academic judgment to take account of learners' circumstances and characteristics, hence not always indicative of an automatic referral to the Nursing and Midwifery Council. A recurrent example of this related to learners' transition into higher education signalling that decision-making for nurse educators is both complex and context specific, and importantly requires a proportional response:

'It depends on the circumstances. I'm not convinced that this would be a good use of public resources'

'Depends on the context - need for professional judgment to be exercised but there should be a consistent approach'

'That could be too heavy-handed. Some post-registration students have been out of education for a while, and may just be getting used to academic life again'

'Again the context of the misconduct is important, but these are not 'black and white' situations'

The quantitative and qualitative findings in this study were broadly supportive of Fitness to Practise processes operating in the higher education arena as the appropriate forum to manage major plagiarism by professional learners to respond to complex decisionmaking in professional programmes. The qualitative findings did however illuminate some tensions with Fitness to Practise processes, in particular, being 'overly bureaucratic' and 'dubiety in managing major plagiarism equitably and transparently' when this involved postqualified learners. Also evident were differential opinions relating to the position and involvement of health service employers, particularly when they were commissioning 
courses/funding fees, and multilayer governance processes which nurse learner may be subject to, that is institutional governance processes plus those linked to Fitness to Practise. Qualitative commentary appeared to support Fitness to Practise as the preferred mechanism to investigate and adjudicate on major plagiarism by nurse learners.

\section{$\underline{\text { Role dimensions for the nurse educator }}$}

Contemporary nursing practice is indicative of a complex role which involves mastery of the art and science of caring, which is underpinned by the ideology of professionalism (Lane, 2010; Nursing and Midwifery Council, 2015). As the linchpin, professionalism is representative of a multidimensional concept, which is described and debated in a variety of ways depending on the perspective from which it emerges and the traits attributed to it (Adams, 2010). Scott (2008) suggests professionalism in nursing has emerged in a disciplinary context fostered by patient-focused, egalitarian, values-based care delivery. Starc (2009) indicates that professionalism has emerged within nursing via the demise of its historical subservience and allegiance to medicine and now reflects practitioners with advanced knowledge and levels of practice drawn from a legitimate research base which are subsequently associated with high level decision-making and greater autonomy. In being more forthright, Semple et al. (2004) lock professionalism into professing and becoming guardians of values, namely honesty and integrity. What is evident is that professionalism represents competency in practice formed as a consequence of the tripartite relationship between knowledge, skills, and values and therefore has clear implications for the role of the nurse educator in terms of its promotion.

The concept of professionalism, and its assessment, is universally infused within the nursing literature on academic dishonesty, within which plagiarism, when mentioned, is subsumed. In some instances, whist this includes reference to the impact academic dishonesty may have on learners accruing knowledge and understanding, the propensity is to focus the discussion on how this challenges professional integrity and ethics. However, as an educational counter to the numerous comments regarding plagiarism which are permeated with ethical overtones, Briggs (2003, p. 22) suggests that: 
'The problem with the moralistic attitude underpinning policies of plagiarism is that such moralism is so institutionalised - and so easily offended - that we are prone to forget the very straightforward and obvious idea that plagiarism constitutes a learning and communication problem too'

In pursuing lines of inquiry associated with professionalism and plagiarism, Table 4 outlines findings on a range of variables associated with role implications for supporting learning and promoting professionalism within nurse education in relation to plagiarism. This resulted in statistically significant responses for all 8 statements, in which nurse educators confirmed their primary role as being pedagogical; but nonetheless included high-stakes responsibility in the development of safe and effective practitioners, which for nurse educators, recognises implications exist beyond the campus setting.

\begin{tabular}{|c|c|c|c|c|c|c|}
\hline \multirow{2}{*}{$\begin{array}{l}\text { Table } 4 \\
\text { Statement }\end{array}$} & \multirow[b]{2}{*}{ Total } & \multicolumn{2}{|c|}{ Reject } & \multicolumn{2}{|c|}{ Endorse } & \multirow[b]{2}{*}{$\chi^{2}$} \\
\hline & & $F$ & $\%$ & $f$ & $\%$ & \\
\hline $\begin{array}{l}\text { 16. The Nurse Educator's primary role in plagiarism } \\
\text { management should be to address pedagogical } \\
\text { deficits in referencing, paraphrasing and writing skills }\end{array}$ & 156 & 42 & 26.9 & 114 & 73.1 & $33.23^{*}$ \\
\hline $\begin{array}{l}\text { 17. Nurse Educators should not expect having to } \\
\text { make explicit to learners (pre and post-registration } \\
\text { level), the negative relationship which exists between } \\
\text { plagiarism and professional values }\end{array}$ & 159 & 124 & 78.0 & 35 & 22.0 & $49.81^{*}$ \\
\hline $\begin{array}{l}\text { 18. Nurse Educators should make explicit to learners } \\
\text { that plagiarism, whether intentional or unintentional, } \\
\text { may prevent them constructing knowledge for } \\
\text { professional practice. }\end{array}$ & 156 & 9 & 5.8 & 147 & 94.2 & $122.07^{*}$ \\
\hline $\begin{array}{l}\text { 19. In the context of major plagiarism, Nurse } \\
\text { Educators should expect to act as professional } \\
\text { gatekeepers in confirming/disconfirming 'good } \\
\text { character' as part of an Higher Education Institutions } \\
\text { Higher Education Institution's Fitness to Practise } \\
\text { processes }\end{array}$ & 145 & 18 & 12.4 & 127 & 87.6 & $81.93^{*}$ \\
\hline $\begin{array}{l}\text { 20. The Nurse Educator's role concerning plagiarism } \\
\text { management has no relevance to the preparation of } \\
\text { practitioners who will be, or are, trusted with caring } \\
\text { and safeguarding the public }\end{array}$ & 159 & 138 & 86.8 & 21 & 13.2 & $86.09^{*}$ \\
\hline $\begin{array}{l}\text { 21. Nurse Educators should not expect a role which } \\
\text { includes informing post-registered learners that an } \\
\text { Higher Education Institutions Higher Education } \\
\text { Institution's procedures for dealing with major } \\
\text { plagiarism could include referral to the Nursing and } \\
\text { Midwifery Council }\end{array}$ & 142 & 102 & 71.8 & 40 & 28.2 & $27.07^{*}$ \\
\hline $\begin{array}{l}\text { 22. The Nurse Educator's role involves ensuring pre- } \\
\text { registration learners are familiar with plagiarism } \\
\text { investigation processes }\end{array}$ & 166 & 7 & 4.2 & 159 & 95.8 & $139.18^{*}$ \\
\hline $\begin{array}{l}\text { 23. Nurse Educators should not be deterred in } \\
\text { managing plagiarism by the prospect of learners } \\
\text { returning negative evaluations/damaging the student- } \\
\text { teacher relationship }\end{array}$ & 165 & 4 & 2.4 & 161 & 97.6 & $149.38^{*}$ \\
\hline
\end{tabular}

In an attempt to avoid skewing responses in favour of twinning learning and professionalism, statement 16, 'The Nurse Educator's primary role in plagiarism management 
should be to address pedagogical deficits in referencing, paraphrasing and writing skills', was intentionally introduced to explore what the primary role might reflect in managing plagiarism. This appeared a relevant area of exploration based on Fontana's (2009) qualitative study which, although being focused broadly on academic dishonesty, identified the Nurse Educator's primary role as a professional gate keeper based on learners' capacity to demonstrate ethical behaviour. Consequently, statement 16 did not avoid direct reference to professional values; nor did it, from an organisation standpoint, make reference to adhering to a higher education institution's strategic policy, which arguably might also have been a consideration regarding role implications. In allowing participants to reject or confirm, solely on the basis of pedagogy, the findings established $73.1 \%(n=114)$ of opinions in favour of the academic precedent. These findings therefore appear to contrast with the empirical nursing literature by Fontana (2009) and moreover, concur with Briggs's (2003) expression of plagiarism, which fundamentally places dealing with it in a learning context.

In relation to the statements outlined in Table 4, some participants took the opportunity to offer additional qualitative comments. With specific reference to the primary role nurse educators should establish regarding plagiarism management, none alluded to professional gate keeping as being paramount. They did, however, commonly offer comments under the emergent theme of professionalism in academic settings, which consistently indicated that the professional context must also feature as part of the educational role:

'Certainly the students need to have clarity about what defines plagiarism, but the nurse educator's role is wider than this. It also includes nurturing the ethical and professional aspect of life'.

'Although I agree it should be our primary role, we probably also have a role in ensuring future vigilance with intentional acts of plagiarism as this may be in indicator of other professional concerns'

'It is an important role of the nurse educator to assist the learner to make sense of these difficult concepts [plagiarism], highlighting how they interface and the implications for their professional practice and personal integrity of intentional academic misconduct'

It was apparent within the comments offered that it is the general disposition of nurse educators to adopt a balanced approach which embraces the educational and professional elements. These are clearly opinions that are not generally reflected in the nursing literature. 


\section{DISCUSSION}

The complexities of governing plagiarism in higher education argue for responsive policies (Higher Education Academy, 2011). In concurring, nurse educators endorsed the need for comprehensive and transparent policies to enable equitable plagiarism management. Importantly, these should include reference to the requirement of professional learning vis-à-vis, Fitness to Practise which few Scottish institutions evidence to capture additional governance processes. The deficiencies uncovered within higher education institutions' policies in articulating the duality of governance requirements linked to professional learning, suggest the need for a review of higher education institution policy practices.

Against this backdrop, this study illuminated opinions regarding the interface of governance processes, particularly when this involved major plagiarism and the post qualified learner. In pragmatic terms, participants endorsed Fitness to Practise processes as a viable forum to manage major plagiarism, irrespective of the learner's pre or post registration status, in order to protect the public. However, some nurse educators suggested debate exists regarding the status of Fitness to Practise process within higher education, that is, whether this should operate in addition to or exclusive of the existing higher education institution's plagiarism governance processes, where the primary focus is disciplinary. With different understandings of how the Fitness to Practise mechanism should operate in the higher education context, a review of organisational functionality appears rational.

In managing plagiarism, and the inherent role implications, nurse educators in this study opined this as primarily a pedagogical concern. Consequently, the results of this study did not concur with opinion based nursing literature, which appear dominated by professional probity perspectives, namely ethical gate keeping. Additionally, the twinning of the pedagogical and professional domains in managing plagiarism confirms that any role occupied by the nurse educator has implications beyond the campus perimeter, succinctly, on the quality and safety of patient care.

The implications from this study suggest further research is required to advance discrete and diverse lines of inquiry to explore nurse educators' experience of implementing plagiarism policies and decision making; the relationship between higher education 
institutions and National Health Service employers with regard to their involvement in plagiarism management of the post-qualifying nurse learner; and a comparative study of plagiarism governance involving educators from other professionally-based subject areas which also require adhering to Fitness to Practise requirements in the higher education setting.

\section{Limitations and Strengths}

This study was subject to limitations, which may have impacted on the findings. The questionnaire developed for this study aimed to be succinct and comprehensive to investigate and elicit responses within a time frame which participants would not perceive as onerous. However, reflection suggests in reference to statements 9 and 10 (Table 2), that in probing nurse educators' opinions of the behavioural manifestations associated with plagiarism, this could have been more precise, that is providing separate statements on the behavioural typologies such as literary theft (non-legal context), fraud, cheating and rule breaking. Whilst this would have extended the length of time required for completion of the questionnaire, this would have been beneficial in relation to specifically exploring the variable of 'literary theft', which, although it appears in many dictionary references, and commonly referred to in the literature on plagiarism, was not used within any of the higher education institutions' policies (documentary analysis). This would have been a relevant dimension to explore based on the Nursing and Midwifery Council's assessment of major plagiarism which uses 'Dishonesty in Theft' to adjudicate on plagiarism cases referred to their Conduct and Competence Panel. The response rate $(44 \%)$ was arguably low, however this did compare favourably with other web-based surveys.

This study's strength is its representation of national survey of nurse educators' opinions on the complex and emotive topic of plagiarism, which considers the fusion between educational and professional governance processes with regard to professional learning and the role of the nurse educator. Given the level of statistically significant outcomes, it is argued the findings from this study can be cautiously generalised to the UK, and beyond, depending on the governance stipulations of institutions offering nurse education and the affiliated professional statutory bodies. 


\section{CONCLUSION}

This study demonstrates the need for connectivity between institutional and professional governance processes to contribute to the management of plagiarism in nurse education. The outcomes indicate the need for a responsive governance framework to support the consistent, transparent and proportional management of plagiarism for nurse education. Underlying the governance requirements is recognition of the complex role of the nurse educator, that of professional educator and professional nurse, which in the context of plagiarism management in nurse education are not mutually exclusive.

Conflict of interests: None

\section{REFERENCES}

Adams, R., 2010. Exploring dual professional identities, the role of the nurse tutor in higher education in the UK: role complexity and tensions. Journal of Advanced Nursing, 67 (4), 884492.

Akhtar-Danesh, N., Baumann, A., Kolotylo, C., Lawlor, Y., Tomkins, C., \& Lee, R., 2011. Perceptions of professionalism amongst faculty and nursing students. Western Journal of Nursing Research 20(10), 1-24.

Baird, C., \& Dooey, P. 2014. Ensuring effective student support in higher education alleged plagiarism cases. Innovation in Higher Education 39, 387-400.

Bavier, A. R. 2009. Holding students accountable when integrity is challenged. Nursing Education Perspectives, 30 (1), 5.

Braun, V., \& Clarke, V., 2006. Using thematic analysis in psychology. Qualitative Research in Psychology, 3, 77-101.

Briggs, R. (2003). Shameless! Australian Universities Review, 46 (1), 19-23.

Brown, C.A., Dickson R., Humphreys, A., McQuillan, V., \& Smears, E., 2008. Promoting academic writing/referencing skills: outcomes of an undergraduate e-learning pilot project. British Journal of Educational Technology, 39(1), 140-156.

Cohen, L., Manion. L., \& Morrison K., 2007. Research Methods in Education (6 ${ }^{\text {th }}$ Ed). London: Routledge.

Fontana, J.S., 2009. Nursing faculty experience of student academic dishonesty. Journal of Nursing Education, 48 (4), 181-185.

George, D., \& Mallery, P., 2003. Cronbach's alpha rule of thumb. SPSS for windows step by step: a simple guide and reference 11.0 update (4th Ed.). Boston, MA: Allyn and Bacon. 
Higher Education Academy JISC Academic Integrity Service, 2011. Policy Works: Recommendations for review policy to manage unacceptable practice in higher education. York: Higher Education Academy.

Hilbert, G.A., 1985. Involvement of nursing students in unethical classroom and clinical behaviors. Journal of Professional Nursing, 1(4), 230-234.

Hilbert, G.A.,1987. Acacemic fraud: prevalence, practices, and reasons. Journal of Professional Nursing, 3(1), 39-45.

de Jager, K., \& Brown, C., 2010. The tangled web: investigating view of plagiarism at the University of Cape Town. Studies in Higher Education, 35 (5), 513-528.

Kennedy, D. (2011). Sherlock Holmes and the case of the plagiarised paper. Nurse Education Today, 3 (5), 525-530.

Kenny, D. (2007). Student plagiarism and professional practice. Nurse Education Today, 27, 14-18.

Lane, I.F., 2010. Professional competencies in health sciences education: from multiple intelligences to the clinic floor. Advanced Health Science Education, 15, 129-146.

Langone, M., 2007. Promoting Integrity amongst nursing students. Journal of Nursing Education, 46 (1), 45-48.

McCrink, A. (2010). Ethical nursing practice: why it should concern us all. Nursing for Women's Health, 14 (6), 443-446.

Nursing and Midwifery Council, 2001. Standards for specialist education and Practice. London: NMC.

Nursing and Midwifery Council, 2004. Standards of proficiency for specialist community public health nurses. London: NMC.

Nursing and Midwifery Council, 2006. Standards of proficiency for nurse and midwife prescribers. London: NMC.

Nursing and Midwifery Council, 2008. Standards to support learning and assessment in practice. London: NMC.

Nursing and Midwifery Council, 2015a. The Code: Professional standards of practice and behaviour for nurses and midwives. London: NMC.

Nursing and Midwifery Council, 2015b. Quality Assurance Framework: for nursing and midwifery education and local supervising authorities. London: NMC.

Nursing and Midwifery Council, 2016. Conduct and Competence Panel Hearings. https://www.nmc.org.uk/concerns-nurses-midwives/hearings-and-outcomes/schedule-and outcomes/ [accessed 22nd February 2016]

Park, E.J., Park, S., \& Jang, I-S (2013) Academic Cheating among Nursing students. Nurse Education Today, 33, 346-352.

Paterson, B., Taylor, L., \& Usick, B., 2003. The construction of plagiarism in a school of nursing. Learning in Health and Social Care, 2 (3), 147-158.

Pence, P., 2012. Plagiarism: using a collaborative approach in an on-line allied health professions course. Nurse Educator, 37 (1), 12-16. 
Robson, C., 2011. Real World Research ( $3^{\text {rd }}$ Ed) Oxford: Blackwell Science.

Sax, L.J., Gilmartin, S.K., \& Bryant, A.N., 2003. Assessing response rates and non-response bias in web and paper surveys. Research in Higher Education, 44 (4), 409-432.

Scott, S.D., 2008. 'New professionalism' - shifting relationships between nursing education and nursing practice. Nurse Education Today, 28, 240-245.

Semple, M., Kenkre, J., \& Achilles, J. (2004). Student fraud: The need for clear regulations for dismissal or transfer form healthcare training programmes for students who are not of good character. NT Research, 9(4), 272-280.

Smedley, A., Crawford, T., \& Coete, L. (2015). An intervention aimed at reducing plagiarism in undergraduate nursing students. Nurse Education in Practice, 15, 168-173.

Starc, A. 2009. Nursing professionalism in Slovenia: knowledge, power, and ethics. Nursing Science Quarterly 22 (4), 371-374.

Sutherland-Smith, W., 2014. Legality, quality Assurance and learning: competing discourses of plagiarism management in higher education. Journal of Higher Education quality and Management 36 (1), 29-42.

Walker, C., \& White, M., 2014. Police, design, plan and manage: developing a framework for integrating staff roles and institutional policies into a plagiarism prevention strategy. Journal of Higher Education quality and Management 36 (6), 674-687. 